\title{
Osteogenesis Imperfecta Type I
}

National Cancer Institute

\section{Source}

National Cancer Institute. Osteogenesis Imperfecta Type I. NCI Thesaurus. Code C99003.

The mildest and most common type of osteogenesis imperfecta. It is characterized by bone fractures, muscle weakness, and loose joints. Bone deformities are either absent or minimal. 